\title{
Investigation of atmospheric conditions fostering the spreading of legionnaires' disease in outbreaks related to cooling towers
}

\author{
Diego Villanueva ${ }^{1}$ (D) $\cdot$ Kerstin Schepanski ${ }^{1}$ (D)
}

Received: 13 May 2019 / Revised: 26 June 2019 / Accepted: 26 June 2019 / Published online: 24 July 2019

(C) The Author(s) 2019

\begin{abstract}
Legionnaires' disease (LD) is a severe lung infection caused by the bacteria Legionella pneumophila which is usually associated with water managing installations like cooling towers. Several outbreaks of LD have been linked to individual sources of bioaerosol in the past. However, the transmission pathways as well as the influence of meteorological factors in the spreading of such bioaerosols remain unclear. Using the meteorological data near 12 LD outbreaks in Europe for the period 2000-2016, the correlation between key meteorological factors and the occurrence of LD was assessed. Temperature, humidity, atmospheric pressure, wind speed, precipitation, cloud cover and, for the first time, fog occurrence were included as potential risk factors. It was found that the occurrence of fog was related to four of the LD outbreaks, suggesting that the presence of fog droplets and/or the thermal inversions associated with fog may play a role in the disease spreading. This finding can contribute to outbreak investigations and to the prevention of future outbreaks.
\end{abstract}

Keywords Legionnaires' disease · Thermal inversion $\cdot$ COSMO $\cdot$ Fog

\section{Introduction}

Legionnaires' disease (LD) is transmitted through the inhalation of bioaerosols from water managing devices containing Legionella pneumophila, a waterborne bacteria (Bartram et al. 2007). Large outbreaks have been linked to cooling towers (CT), (García-Fulgueiras et al. 2003). However, most cases of LD are not linked to a common source and occur sporadically (not related geographically or temporally). Nevertheless, Bhopal et al. (1991) estimated that $28 \%$ of sporadic cases of LD could be linked to CTs in the city of Glasgow during 1978-1986.

Three main types of bioaerosols have been discussed for the transmission of LD: droplets containing L. pneumophila, Acanthamoeba containing L. pneumophila and vesicles expelled from Acanthamoeba containing L. pneumophila (Berk et al. 1998). Despite a large number of studies, uncertainty remains around the nature of the bioaerosols responsible for the transmission (Bouyer et al. 2007).

Diego Villanueva

villanueva@tropos.de

1 Leibniz Institute for Tropospheric Research, Permoser Str. 15, 04318 Leipzig, Germany
Most of the CTs involved in LD outbreaks are small and have less than $300 \mathrm{KW}$ power (Bentham and Broadbent 1993). Such CTs have fan units which maintain an outgas velocity of about $10 \mathrm{~ms}^{-1}$ and are only a few meters tall. They are frequently installed on production sites where hot water needs to be re-cooled. In outbreaks related to CTs, often several units are found to be infected, and the geographic distribution of the infection cases can cover several kilometres (Nguyen et al. 2006). A discrepancy exists between the low concentrations of colony-forming units (CFU) measured in near confirmed LD sources (e.g., aerosol near a CT) and the high concentration required to infect a human being (O'Brien and Bhopal 1993). This is known as the infective dose paradox. It has been postulated that amoebae may cause LD by releasing large numbers of virulent Legionellae in the lower respiratory tract after necrosis.

Fisman et al. (2005) found a strong correlation between the relative humidity $(\mathrm{RH})$ and the sporadic cases of legionellosis in Philadelphia, USA, between 1995 and 2003. Other meteorological parameters such as temperature (Kao et al. 2015; Taiwan), low pressure associated with cyclone passage (Beauté et al. 2016; Europe), precipitation (Cunha et al. 2015; New York City, USA) and low wind speeds (Russo et al. 2018; Portugal) have been also postulated as risk factors in the transmission of LD. 
Additionally, temperature inversions within the boundary layer have been also associated with LD outbreaks related to CTs (García-Fulgueiras et al. 2003). Such a stable atmospheric layer inhibits the horizontal and upward mixing of pollutants promoting higher concentrations of the same. However, it is still uncertain how these atmospheric factors impact the spreading of LD, and whether other atmospheric factors may also play a role.

This study will examine the correlation between several atmospheric factors and the development of $12 \mathrm{LD}$ outbreaks occurring in Europe (Fig. 1) during 20002016. For the first time, the occurrence of fog will be examined as potential risk factor.

\section{Material and methods}

Several LD outbreaks related to CTs occurred in Europe during the past 20 years (Walser et al. 2014), most of them are associated with fatal causalities. For some of these outbreaks, the temporal evolution of the disease onsets could be found in the literature. In the framework of this study, 12 outbreaks in the period 2000-2016 will be examined and tested against the hypothesis that the presence of fog is supporting LD outbreaks. Therefore, we will analyse weather reports from nearby meteorological SYNOP (SYNoptic OPeration) station for LD outbreaks where weather stations are located nearby and thus representing the weather conditions.

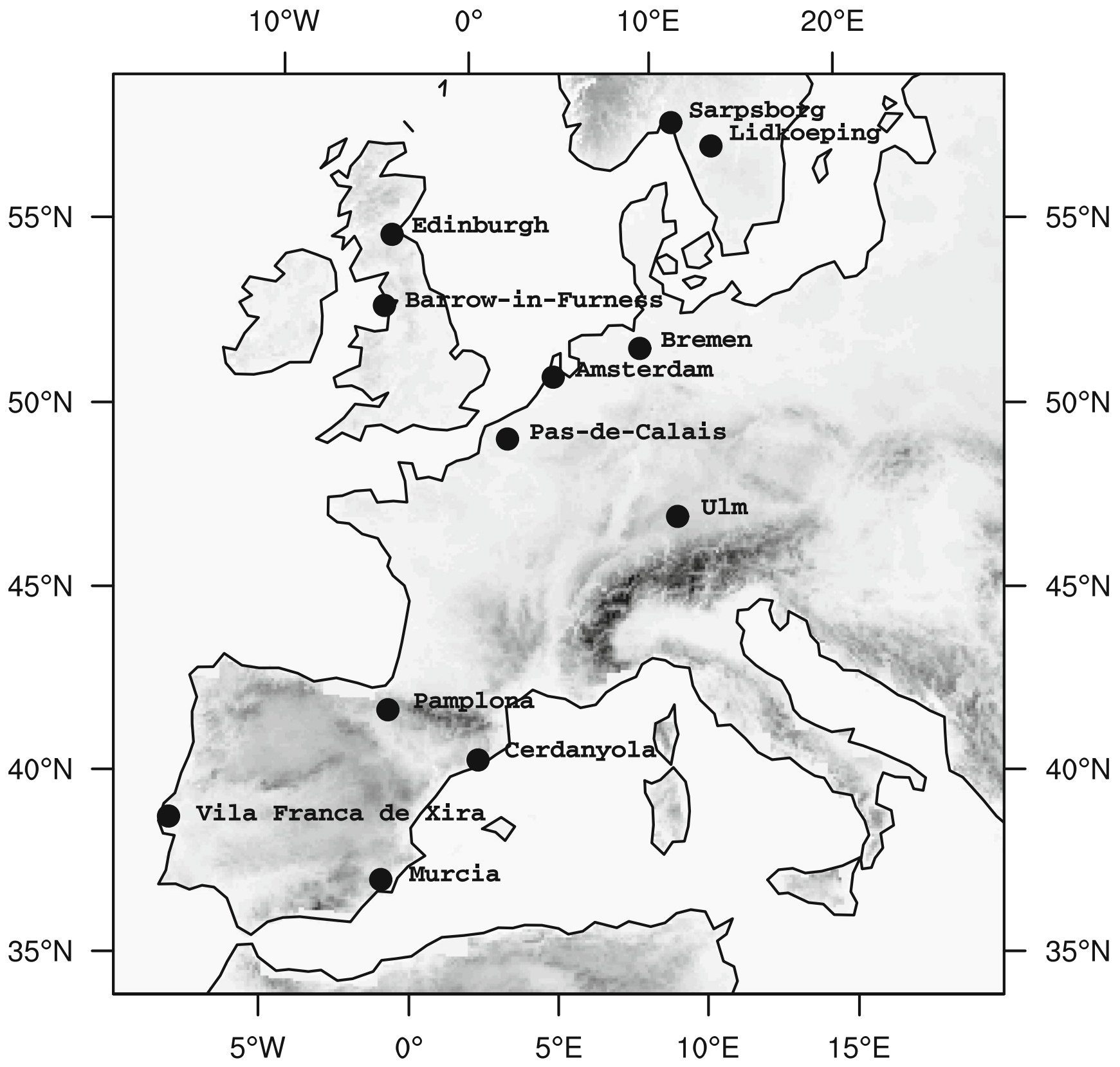

Fig. 1 Location of the 12 outbreaks studied (2000-2016). See Table 1 for the respective time periods of each outbreak 
Weather reports (SYNOPs) indicating fog events were obtained from the National Oceanic and Atmospheric Administration (NOAA), which is collecting SYNOP reports from national weather services from all over the world. In particular, the horizontal visibility indicating fog events was near the 12 outbreaks (see Table 1). Figure 1 shows the locations of these outbreaks. Most of the stations reported horizontal visibility, RH, cloud cover, wind speed, temperature, precipitation, and pressure at hourly resolution. However, the stations near Murcia, Cerdanyola, and Lidköping provided measurements only every $3 \mathrm{~h}$. Moreover, for Sarpsborg and Pamplona observations were available only from 06 to 18 UTC every $3 \mathrm{~h}$. Similarly, for the station near Vila Franca de Xira observations were available every $3 \mathrm{~h}$ but only from 09 to 15 UTC and thus likely to underestimate the occurrence of fog.

In order to match the observed weather condition with the assumed incubation time, the atmospheric parameters of each station were averaged into 3-daily and 7-daily mean values. The number of onset cases, accumulated precipitation, and fog frequency were resampled as 3-daily and 7-daily sums instead. We choose to aggregate the data each 3 days and each week to minimize possible effects of the incubation time variability.

For identifying the presence of fog automatically, the horizontal visibility is found to be a useful parameter (Dupont et al. 2012). The horizontal visibility can be approximated from the extinction coefficient $b_{\text {ext }}$ by the Koschmeider equation (Seinfeld and Pandis 1998):

visibility $=\frac{3.912}{\mathrm{~b}_{\mathrm{ext}}}$

Lower visibility values are caused by the absorption and scattering of light by particles in the air such as aerosols or water droplets. Errors in the estimation of $b_{\text {ext }}$ by scatterometers result in a standard deviation of about $10 \%$ over a range of visibility from about $100 \mathrm{~m}$ to $50 \mathrm{~km}$ (WMO 2008). In the following study, fog is defined as conditions with visibility lower than $1 \mathrm{~km}$ (Vautard et al. 2009). The daily fog frequency was then calculated for each station as the number of fog detections per day. Different meteorological stations have different measurement frequencies, and therefore the daily fog frequency cannot be compared directly between stations. Nevertheless, the time series of fog frequency can be used to assess the impact of fog conditions in the spreading of LD at each individual outbreak.

Egan et al. 2011 found that the incubation periods for LD cases after the exposure during an outbreak in Melbourne (Greig et al. 2004) were best fitted by a gamma probability distribution (shape parameter $a=4.96$ and inverse scale parameter $b=1.27)$. With this distribution, the best estimate of the transmission date is at a median of 6 to 7 days before each onset case. Using this information, for each outbreak, the lag- 
correlation (Pearson correlation coefficient) was calculated between the number of LD onsets and the atmospheric parameters with a 7-day lag. Additionally, the $p$ value for testing non-correlation is calculated. This number roughly indicates the probability for the calculated correlation to result from an uncorrelated environment. Due to the explorative nature of this study, we consider $p$ values less or equal to 0.1 to be significant enough for our purposes (Stigler 2015). Figure 2 shows the number of case onsets for each outbreak and the expected transmission cases per day using the incubation times found by Egan et al. 2011 and described above.

The formation of fog requires stable boundary layer conditions. As measurements on boundary layer stability are sparse and not available for any meteorological observation site included in this study, model analysis from the meso-scale atmosphere model COSMO-DE (COnsortium for Small-scale Modelling) operated by the Deutscher Wetterdienst (DWD) were used (Dengler et al. 2009; Doms et al. 2016). The model includes a data assimilation process based on a nudging method (Schraff 1997). The horizontal resolution for the COSMODE model is $2.8 \mathrm{~km} \times 2.8 \mathrm{~km}$, and the output frequency is hourly; each single simulation offers forecasts of up to $27 \mathrm{~h}$. The vertical coordinate consists of 49 hybrid levels (following the terrain near the surface) up to $22 \mathrm{~km}$ height and the domain size for each city is $0.8^{\circ} \times 0.8^{\circ}$. We note that only the analysis data as provided by the DWD were included in this workand not the forecasts. To reflect the atmospheric conditions for each city, model data were averaged over small domains $\left(0.8^{\circ} \times 0.8^{\circ}\right)$ centred at each city. For each outbreak, 2 weeks of model analysis were studied starting 1 week before the first reported LD case indicating the onset of the LD outbreak. The model analysis from the COSMO-DE model from the DWD was available for two locations in Germany. These are the outbreaks occurred in Bremen 2015-2016 (two outbreaks separated by 3 months) and the outbreak in Ulm 2009.

\section{Results}

To understand the impact of meteorological conditions in the spreading of outbreak-related LD, we should first consider that each outbreak occurred at a different location and season. Table 1 shows the main characteristics of the outbreaks studied. The outbreaks occurred between 2001 and 2016, with only three outbreaks (Bremen, Vila Franca de Xira and Edinburgh) occurring after 2010. Seven of the outbreaks occurred totally or partially during summer. The outbreaks duration ranged from 21 to 71 days. The two outbreaks that occurred in Bremen, and which were separated by a 3month break, are considered as two different outbreaks for the analysis here. Four out of the twelve outbreaks studied occurred at latitudes lower than $45^{\circ} \mathrm{N}$ (Murcia, Pamplona, Cerdanyola and Vila Franca de Xira). These four outbreaks occurred in average during warmer $\left(18\right.$ to $\left.26^{\circ} \mathrm{C}\right)$ and dryer $(51$ to $71 \% \mathrm{RH}$ ) conditions than the rest of the outbreaks. During each of these 'warm' outbreaks more than 100 LD cases were reported, and no fog events were recorded in the SYNOP stations in the 2 weeks previous to the outbreaks. However, these stations have also the lowest measurement frequency of the study with only 3 to 8 measurements a day which increases the chance for non-identified fog events. In contrast, for 5 of the 8 outbreaks occurring north of the $45^{\circ} \mathrm{N}$ latitude (Bremen, Edinburgh, Lidköping, Pas-de-Calais and Ulm) at least one
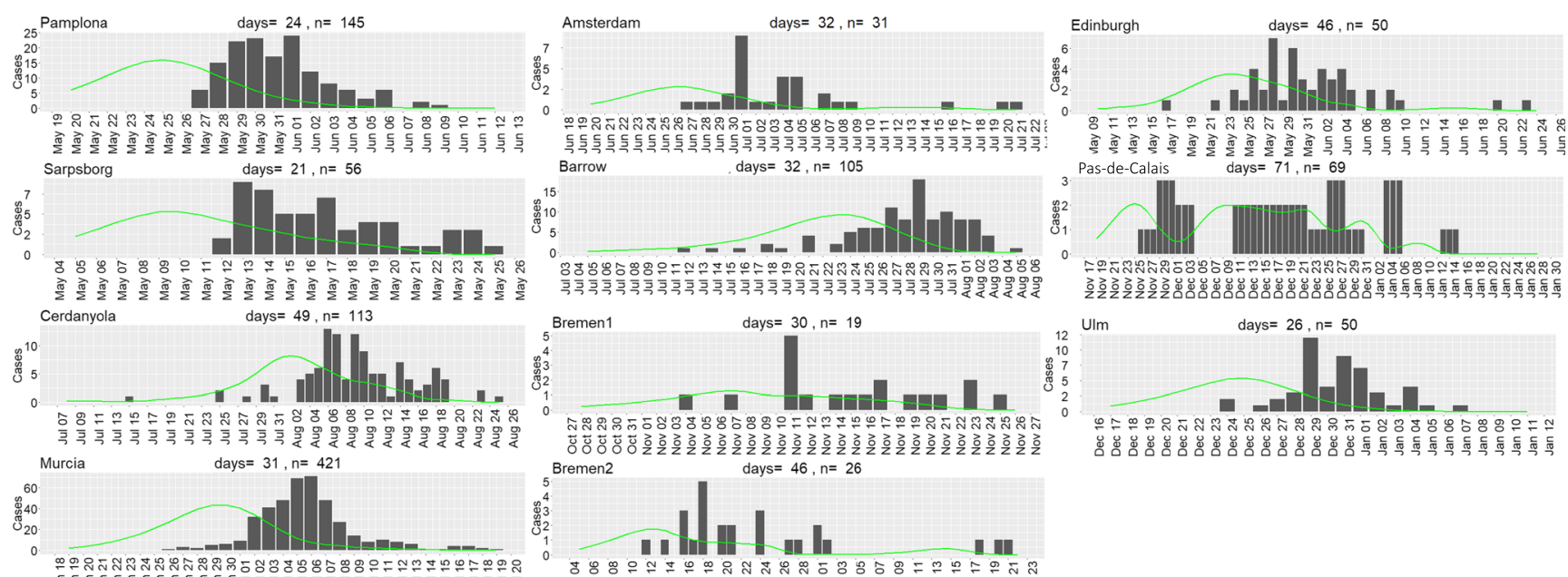

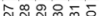

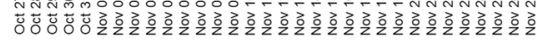
Bremen2
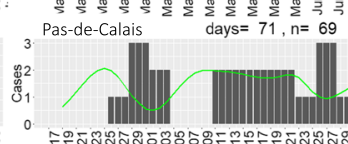

든ㄷำ

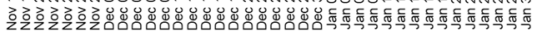

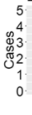
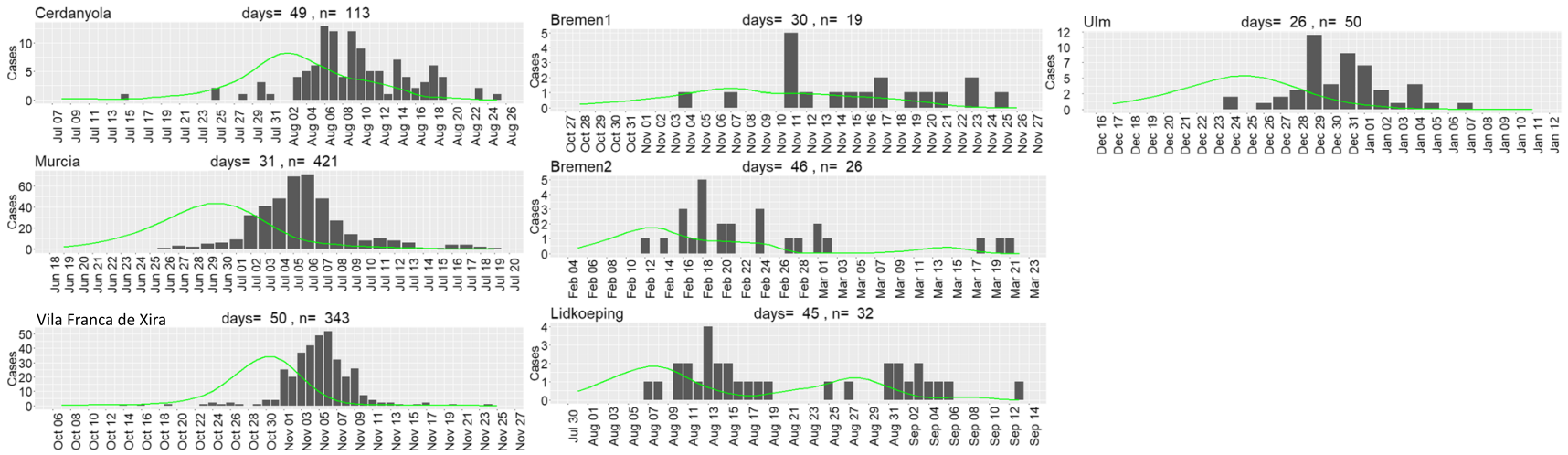

Fig. 2 Temporal evolution of the number of legionellosis onset (bars) and the expected transmissions per day (green line) 
fog event was detected in the 2 weeks previous to the outbreaks.

\section{Correlation between meteorological parameters and disease onset}

Table 2 shows the time correlation between the estimated transmission of LD and the different meteorological parameters available in order to test the hypothesis that fog supports LD outbreaks. For all 12 outbreaks, the temperature was measured at the nearest SYNOP station. The 3-daily lag-correlation between the cases onsets and the air temperature 7 days before was significant $(p<0.1)$ and positive for three outbreaks (Lidköping, Edinburgh and Murcia). This partly confirms the previous findings by García-Fulgueiras et al. (2003) and Ulleryd et al. (2012). Both studies pointed out that the probable date of infection coincided with warmer weather conditions.

For all 12 outbreaks, RH was also an available measure. The resulting 3-daily lag-correlation between $\mathrm{RH}$ and the cases onsets was significant $(p<0.1)$ for three outbreaks but positive for only two (Pas-de-Calais and Barrow-in-Furness). None of the publications following the outbreaks in Pas-de-Calais and Barrow-in-Furness mentioned the potential influence of humidity in the disease spreading. However, the influence of humidity in LD transmission has been already shown for sporadic cases of LD in the past (Fisman et al. 2005).

For 10 of the 12 outbreaks considered here, the surface pressure was available at the nearest SYNOP station, and the 3-daily lag-correlation with the cases onsets was significant $(p<0.1)$ for three of the outbreaks but negative only for Ulm. Nevertheless, the influence of low pressure has been shown for several community-acquired LD cases (not related to a specific source) in Europe (Beauté et al. 2016).

For all 12 of the outbreaks, wind speed measurements were available but the 3-daily lag-correlation was significant $(p<0.1)$ only for Lidköping (negative correlation). The influence of low wind speeds, related to atmospheric stagnation conditions, has been postulated as an important factor during the outbreak occurred in Vila Franca de Xira (Russo et al. 2018; Shivaji et al. 2014). For this last outbreak, a weekly negative lag-correlation $(p=0.19)$ was found between wind speed and cases onsets.

Daily precipitation $(\mathrm{mm} / 24 \mathrm{~h})$ was reported for all stations. However, the 3-daily lag-correlation between precipitation and LD cases onsets was positive and significant $(p<0.1)$ only for Bremen (two outbreaks separated by 3 months). Monthly precipitation has been found to be strongly correlated with sporadic LD in previous studies (Cunha et al. 2015; Hicks et al. 2007). Cloud cover was reported for 9 of the studied stations. However, only the positive weekly lagcorrelation between cloud cover and the cases onsets in Murcia was significant $(p<0.1)$.
The 3-daily lag-correlation between fog frequency and the LD cases onset was significant $(p<0.1)$ for four outbreaks (Edinburgh, Lidköping, Bremen and Pas-de-Calais) and positive for all four. In other words, for four out of five outbreaks where fog events were detected the correlation was significant and positive. For these outbreaks, Fig. 3 shows the 3-daily fog frequency together with the estimated number of LD transmissions. For Lidköping (3-hourly measurement frequency), a single fog event was detected before the outbreak on the 5th August 2004, 8 days before the peak of the outbreak. In Pasde-Calais during October 2003 and April 2004, the maximum fog occurrence ( $31 \mathrm{~h}$ of fog within 3 days) coincides with the start of the estimated transmission ( 7 days before the first case onset) on the 27th November 2013. Additionally, during the whole transmission period in December 2003, the fog occurrence remained high (mostly 5 or more hours of fog within 3 days). For Edinburgh, the first fog event after 2 months occurred on the 22nd May 2012 and lasted 3 h, 8 days before the peak of the outbreak.

Finally, the consecutive outbreaks in Bremen offer a useful opportunity to analyse the meteorological dependency of the outbreaks during a very long time-range with a total of 6 months studied. The source could not be found after the first outbreak, and it is likely that it remained active and infectious until the second outbreak. This assumption is supported by the genetic investigation made by the German Robert Koch Institute, which found a similar genetic pattern in the bacteria during the patient sampling in both outbreaks. On the 3rd November 2015, 8 days before the peak of the first outbreak in Bremen a fog event lasting $23 \mathrm{~h}$ took place. This was the longest fog event of the period September 2015-March 2016, and it occurred the day before the first LD case of the whole outbreak. Similarly, on the 13th February 2016, 5 days before the peak of the second outbreak, a fog event lasting $9 \mathrm{~h}$ took place. No fog events lasting longer than $1 \mathrm{~h}$ took place between the first and second outbreak in Bremen (a total of 78 days) with the exception of a fog event on 21st Jan 2016. However, the cold conditions at this time (down to $-10{ }^{\circ} \mathrm{C}$ ) may have hindered the survivability of the bacteria.

Using the analysis data from the atmospheric model COSMO-DE, the accompanying boundary layer characteristics for three of the outbreaks were studied. In particular, the atmospheric stability and atmospheric water content, both related to the formation of fog, could be assessed. Figure 4 shows the specific cloud water content, as a proxy for fog, and the vertical temperature gradient for three LD outbreaks as an average of the total $0.8^{\circ} \times 0.8^{\circ}$ domain centred at each city. During the outbreak in Ulm (winter), some thermal inversions can be observed close to the ground (identified by positive temperature gradients) before the outbreak from 15th to 23rd December 2009. However, on the 24th December ( 5 days before the peak of the outbreak) a stronger and higher thermal inversion is observed at about $500 \mathrm{~m}$ from the surface. 
Table 2 Pearson correlation coefficient between different meteorological parameters (lagged by 7 days) and the number of LD onset cases

\begin{tabular}{|c|c|c|c|c|c|}
\hline \multirow[b]{2}{*}{ City } & \multirow[b]{2}{*}{ Parameter } & \multicolumn{2}{|l|}{ 3-daily } & \multicolumn{2}{|l|}{ Weekly } \\
\hline & & Correlation & $p$ value & correlation & $p$ value \\
\hline Lidköping & Temperature & 0.49 & $<0.01$ & 0.63 & 0.01 \\
\hline Edinburgh & Temperature & 0.32 & 0.08 & 0.38 & 0.18 \\
\hline Murcia & Temperature & 0.29 & 0.07 & 0.30 & 0.23 \\
\hline Ulm & Temperature & & & -0.29 & 0.23 \\
\hline Pas-de-Calais & RH & 0.34 & $<0.01$ & 0.43 & 0.02 \\
\hline Barrow-in-Furness & $\mathrm{RH}$ & 0.27 & 0.09 & 0.36 & 0.14 \\
\hline Bremen & $\mathrm{RH}$ & & & 0.20 & 0.29 \\
\hline Murcia & RH & -0.37 & 0.02 & -0.46 & 0.06 \\
\hline Edinburgh & Pressure & 0.46 & 0.01 & 0.64 & 0.01 \\
\hline Pamplona & Pressure & 0.40 & 0.03 & 0.43 & 0.14 \\
\hline Murcia & Pressure & 0.19 & 0.23 & 0.34 & 0.16 \\
\hline Bremen & Pressure & -0.17 & 0.15 & -0.22 & 0.22 \\
\hline Ulm & Pressure & -0.46 & $<0.01$ & -0.53 & 0.02 \\
\hline Pamplona & Wind speed & & & 0.32 & 0.28 \\
\hline Murcia & Wind speed & -0.17 & 0.28 & -0.25 & 0.31 \\
\hline Edinburgh & Wind speed & -0.23 & 0.22 & -0.29 & 0.32 \\
\hline Lidköping & Wind speed & -0.35 & 0.02 & -0.50 & 0.04 \\
\hline Vila Franca de Xira & Wind speed & & & -0.33 & 0.19 \\
\hline Bremen & Precipitation & 0.23 & 0.05 & 0.50 & $<0.01$ \\
\hline Murcia & Cloud cover & -0.25 & 0.12 & -0.41 & 0.09 \\
\hline Edinburgh & Fog frequency & 0.56 & $<0.01$ & 0.92 & $<0.01$ \\
\hline Lidköping & Fog frequency & 0.38 & 0.01 & 0.76 & $<0.01$ \\
\hline Bremen & Fog frequency & 0.27 & 0.02 & 0.26 & 0.16 \\
\hline Pas-de-Calais & Fog frequency & 0.22 & 0.06 & 0.35 & 0.06 \\
\hline
\end{tabular}

For each correlation, the daily data over at least 2 months was resampled to 3-daily and weekly values. Only outbreaks for which $p<0.3$ are shown, and values of $p<0.1$ are shown in italics
For both outbreaks that occurred in Bremen, a similar pattern can be observed: a strong thermal inversion near the ground formed 8 to 10 days (2nd to 4th November 2015) and 5 days (13th February 2016) before the peak of the LD outbreaks. These inversions at about 300 to $600 \mathrm{~m}$ from the ground both dissipated during the following day. In both events, a fog layer can be observed from the model analysis. These fog layers were located below a thermal inversion during the week before the peak of the outbreaks (Fig. 4, see marked dates). This suggests that the correlation between fog occurrence and outbreak development might be also a result of the thermal inversions capping a fog layer during the transmission of CT-related LD cases.

\section{Discussion}

Because many different parameters are related to fog formation, the correlation between fog occurrence and LD outbreaks may be a result of other atmospheric parameters having an impact in the development of the outbreak. For example, precipitation can increase the upward fluxes of water vapour favouring the formation of fog by increasing the liquid water content of soil. Additionally, certain types of fog like frontal fogs are directly related to the surface pressure changes associated with frontal systems. Low wind speeds are associated with atmospheric stability and are therefore also related to enhanced fog formation. Because radiation fog forms through rapid cooling at the surface, higher temperatures during the day followed by strong night cooling can lead to high humidity during the morning and can result in fog formation. In summary, several atmospheric parameters considered as potential risk for LD transmission can be in some way related to conditions favourable to the formation of fog. Therefore, fog occurrence as a risk factor for LD transmission has the potential of explaining other atmospheric parameters already postulated as risk-enhancing factors. Unfortunately, the small sample size used in this work limits the confirmation of such possibility, and much work remains to be done in future investigations.

It is difficult to disentangle the effects of fog, $\mathrm{RH}$, and precipitation. On one side, RH and precipitation foster fog conditions, which could explain some of the effects of $\mathrm{RH}$ and precipitation. 

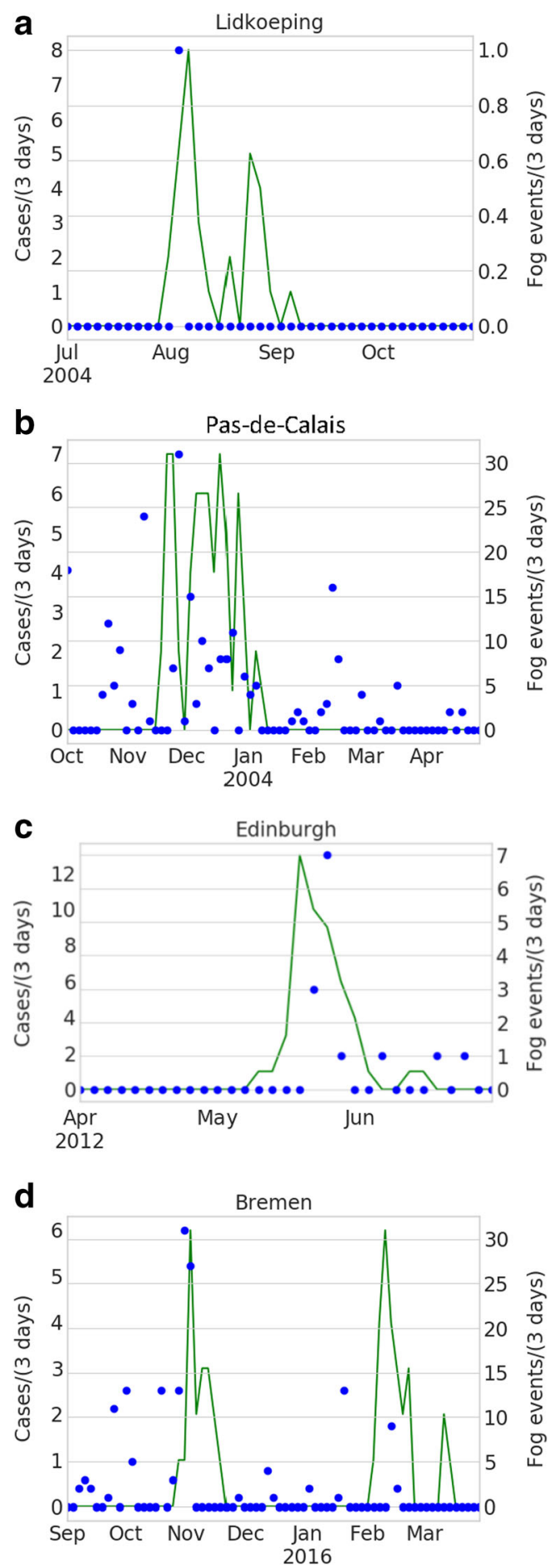

Fig. 3 Time series of the frequency of fog events (blue circles) and estimated number of LD transmissions (green line; number of disease onsets shifted 7 days back in time). Only outbreaks with a significant $(p<0.1)$ correlation are included

On the other side, fog droplets, as well as bioaerosols, may dry out even at high RH. We hypothesise that the constant supersaturation of water vapour during fog conditions is key to the survival of the bioaerosol during certain outbreaks. Such conditions may not be warranted by high $\mathrm{RH}$ and precipitation alone.
Nevertheless, RH and precipitation may be related to other long-term mechanisms, which are independent to the effect of fog. For example, high RH and precipitation in the long-term may foster the growth of Legionellae at potential sources on the ground (Fisman et al. 2005). In our study, it is difficult to prove whether or not fog conditions lead to a similar enhancement of Legionellae growing at Legionellae sources. The analysis of a long-time series of sporadic case at a certain location could evaluate this hypothesis. However, fog occurrence is a relative rare event in most regions, and therefore, such longterm effects may be of minor importance relative to the longterm effects of RH and precipitation.

Although the droplet-size distributions vary greatly between different fog types and events, most types of fog droplets range between 1 and $30 \mu \mathrm{m}$, and the water liquid concentrations are usually higher than $0.1 \mathrm{~g} \mathrm{~m}^{-3}$ even for conditions with visibilities higher than $1 \mathrm{~km}$ (Zak 1994). On the other side, most cases of LD are sporadic and are often linked to domestic water systems like shower heads (Bartram et al. 2007). Inside a shower cabin, about a half of the water mass can be found in droplets of diameters between 2 and $20 \mu \mathrm{m}$, with liquid water concentrations of up to $0.01 \mathrm{~g} \mathrm{~m}^{-3}$ (Zhou et al. 2007). Similar water droplets distributions have been measured under fog conditions (Zak 1994). It can be therefore postulated that during fog the environmental conditions and droplet-size distributions are similar to those inside shower cabins and could therefore indicate a common proxy for LD spreading. Moreover, droplets of such large sizes may be capable of hosting infected amoebae but would evaporate rapidly in undersaturated conditions with a rate of 3 to $12 \mu \mathrm{m}^{2} \mathrm{sec}^{-1}$ with a RH of $99 \%$ and $96 \%$, respectively and at $25^{\circ} \mathrm{C}$ (Duguid and Stampfer 1971). Therefore, it is possible that the high humidity present in both fog and in-shower conditions enable the transport of bacteria or amoebae inside droplets that could not otherwise reach a sufficiently large size to act as proxy.

In most cases, the dispersion of Legionella-containing bioaerosols emitted from CTs has to occur towards the surface in order to infect the population. The presence of thermal inversions favours this transport to the ground, while higher humidity levels may enhance bacteria survivability near the ground. Both environmental conditions are usually present in fog events, possibly resulting in high concentrations of virulent pathogens. Both factors could alone explain the influence of fog in the LD spreading from CTs. However, more investigation would be required to attribute the correlation found between fog occurrence and LD cases to one or both of these factors. Additionally, it is possible that fog conditions may foster the spreading of Legionella from ground sources other than CTs, like for example puddles on roads (Sakamoto et al. 2009).

The results from the COSMO-DE analysis data provided by the DWD suggests that fog occurrence could be successfully prognosed using short-term local atmospheric models 


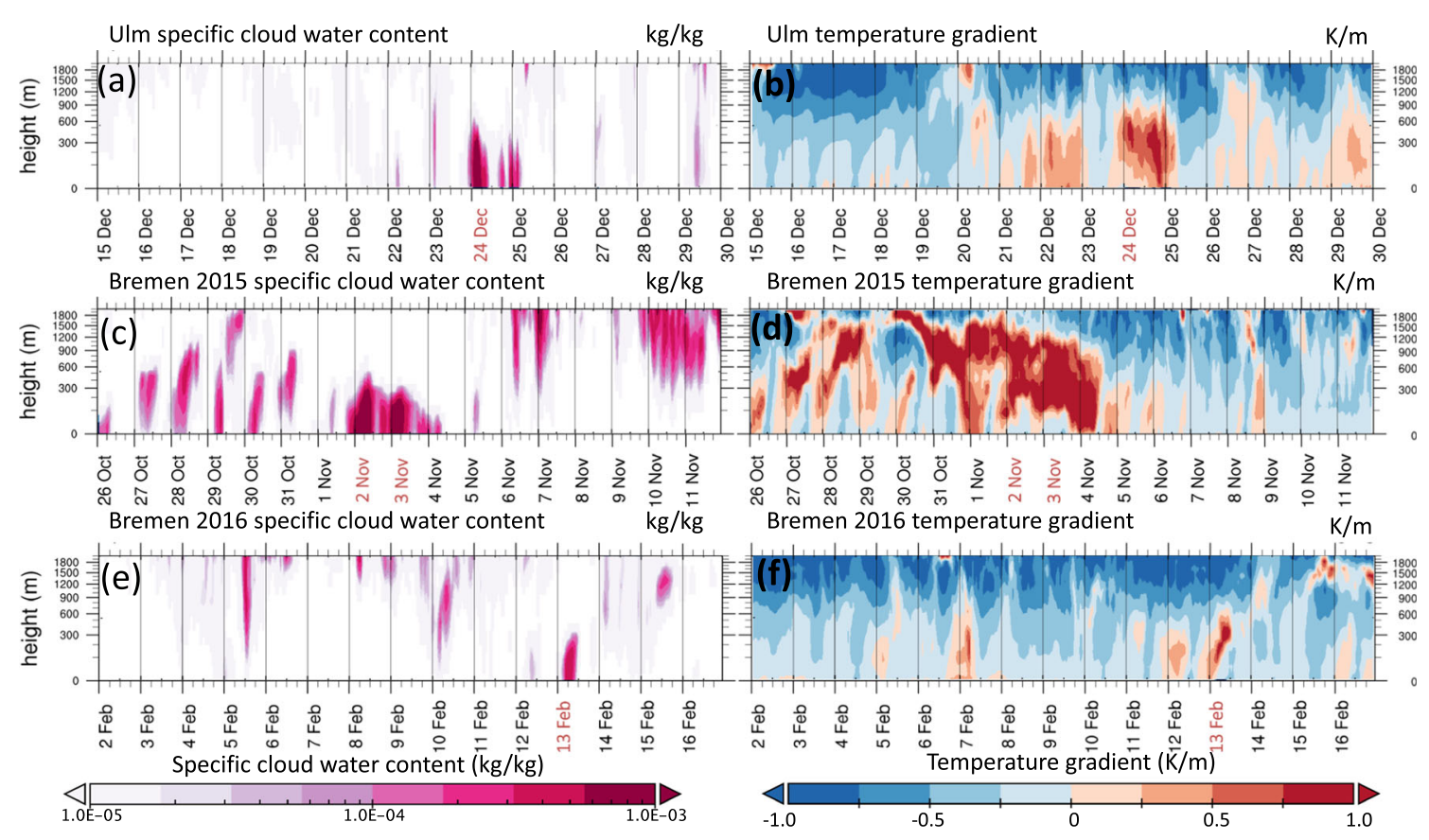

Fig. 4 Vertical profiles of specific cloud water content and temperature gradient for the three outbreaks with available data. Results from the COSMO model as provided by the Deutscher Wetterdienst (DWD).

The red coloured dates represent the day of the respective fog events derived from the horizontal visibility measured at the SYNOP stations

(Bott and Trautmann 2002; Müller et al. 2010). If fog occurrence is suspected to be a recurrent risk factor in a certain location, this opens the possibility of a LD risk prognosis based on predictions of fog occurrence. This has the potential to become, with further development, a new tool in the prevention of $\mathrm{LD}$ outbreaks in the future.

To link the disease onsets with meteorological conditions, it is crucial to narrow down the time of exposure to the bioaerosol, as well as the location of the exposure. For sporadic cases, the time of exposure can only be crudely estimated, while for outbreaks the exposure time can be narrowed down with more precision. Similarly, the travel history of infected individuals for sporadic cases is rarely available, and thus the location of the exposure can be better estimated for outbreak cases than for sporadic cases. Additionally, we are not aware of publicly available data containing the information for sporadic cases of LD. Nevertheless, we encourage future studies to include sporadic cases when studying the influence of meteorology in LD spreading.

The low number of CT-related outbreaks available results in a high uncertainty of the fostering potential of fog and no evidence was found for the relevance of fog in warmer climates. Additionally, correlation between LD and fog was found to be highest for the outbreaks in cold climates where the number of cases is low compared with warmer regions.

Because we focus in this study on meteorological aspects during the time range of the disease spreading, the correlation analysis is limited by the short duration of the outbreaks (typically 20 to 50 days). Therefore, the total number of days included for the correlation analysis is very low in comparison with studies of sporadic LD cases (Fisman et al. 2005) or community-acquired LD not related to a specific source (Beauté et al. 2016). In such studies, the larger number of cases gathered through longer time periods or wider geographic areas result in much larger sample sizes. However, the study of CT-related outbreaks offers the opportunity to narrow down the transmission to a much shorter time period and a geographic area of $10 \mathrm{~km}$ radius from the potential source or less (Nguyen et al. 2006). Therefore, this smaller temporal and geographic domains allow a more confident attribution of local atmospheric conditions to the development of the outbreaks studied.

As mentioned in the last section, for four out of the six outbreaks near a station with hourly resolved visibility measurements, at least one fog event was detected in 2 weeks previous to the first LD case. In contrast, this was the case for only one out of the six outbreaks near stations with 3 to 8 measurements per day. The sporadic nature of fog makes its detection less probable for the latter stations so that the influence of fog cannot be fully discarded for such outbreaks.

The low sample sizes for each outbreak result in a relative low significance (high $p$ values) for most of the correlations calculated for the different atmospheric parameters. Because of the essential data limitations that arise from the study of cooling tower related outbreaks, to achieve a larger sample size, it would be necessary to add more outbreaks to the analysis. This could be accomplished through more post-outbreak epidemiological investigations of the cases onset timing in the 
future. These investigations should incorporate the information from local atmospheric models able to reconstruct the weather conditions during the outbreaks to cope with missing station data near the outbreaks.

\section{Conclusions}

A set of 12 LD outbreaks in Europe were analysed regarding the meteorological conditions present during the pre-onset incubation phase. The different outbreaks studied occurred across a large variety of meteorological conditions, demographic characteristics and potential Legionnaire's disease sources. Despite these differences, the data gathered from the SYNOP stations nearby the outbreaks illustrate in concert with the epidemiologic curves of the outbreaks that a significant $(p<0.06)$ correlation exists between the antecedent occurrence of fog and the temporal evolution of the outbreaks for four of the eight outbreaks occurred in Europe at latitudes higher than $45^{\circ} \mathrm{N}$ (Edinburgh, Lidköping, Bremen, Pas-deCalais). Fewer outbreaks showed a significant $(p<0.1)$ correlation with high temperature (3 outbreaks out of 12 ; Lidköping, Edinburgh and Murcia), high relative humidity (2/12; Pas-de-Calais and Barrow-in-Furness), low pressure (1/10; Ulm), increased precipitation (1/12 Bremen) and low wind speeds (1/12 Lidköping). However, more evidence is needed to establish the role of fog events for Legionellae dispersion with more confidence. In particular, whether the occurrence of supersaturated conditions (fog droplets) or the accompanying atmospheric stability could be the first order controlling mechanism on CT-related Legionellae spreading during fog conditions. Measurements of Legionellae concentration and virulence in aerosols around contaminated cooling towers during fog conditions may be a valuable contribution to the risk assessment and ultimate prevention of future Legionnaire's disease outbreaks. Finally, the inclusion of fog occurrence as a potential risky atmospheric condition in future post-outbreak investigations is of crucial importance for the further confirmation of the postulated relationship between fog and Legionnaire's disease.

Acknowledgements The authors thank the Leibniz Research Alliance INFECTIONS' 21 and in particular Thomas Gutsmann, Anne Paschke, Elisabeth Pfrommer and Ulrich Schaible for fruitful discussion. The authors further thank the Deutsche Wetterdienst for good cooperation on the COSMO model.

Open Access This article is distributed under the terms of the Creative Commons Attribution 4.0 International License (http:// creativecommons.org/licenses/by/4.0/), which permits unrestricted use, distribution, and reproduction in any medium, provided you give appropriate credit to the original author(s) and the source, provide a link to the Creative Commons license, and indicate if changes were made.

\section{References}

Bartram J, Chartier Y, Lee JV, Surman-Lee S, Pond K (2007) Legionella and the prevention of legionellosis [WWW Document]. World Heal. Organ. https://doi.org/10.3201/eid1406.080345

Beauté J, Sandin S, Uldum SA, Rota MC, Brandsema P, Giesecke J, Sparén P (2016) Short-term effects of atmospheric pressure, temperature, and rainfall on notification rate of community-acquired legionnaires' disease in four European countries. Epidemiol Infect 144:3483-3493. https://doi.org/10.1017/S0950268816001874

Bentham RH, Broadbent CR (1993) A model for autumn outbreaks of legionnaires' disease associated with cooling towers, linked to system operation and size. Epidemiol Infect 111:287-295. https://doi. org/10.1017/S0950268800056995

Berk SG, Ting RS, Turner GW, Ashburn RJ (1998) Production of respirable vesicles containing live Legionella pneumophila cells by two Acanthamoeba spp. Appl Environ Microbiol 64:279-286

Bhopal RS, Fallon RJ, Buist EC, Black RJ, Urquhart JD (1991) Proximity of the home to a cooling tower and risk of non-outbreak legionnaires' disease. BMJ 302:378-383. https://doi.org/10.1136/bmj.302.6773.378

Bott A, Trautmann T (2002) PAFOG - a new efficient forecast model of radiation fog and low-level stratiform clouds. Atmos Res 64:191203. https://doi.org/10.1016/S0169-8095(02)00091-1

Bouyer S, Imbert C, Rodier MH, Héchard Y (2007) Long-term survival of Legionella pneumophila associated with Acanthamoeba castellanii vesicles: brief report. Environ Microbiol 9:1341-1344. https://doi.org/10.1111/j.1462-2920.2006.01229.x

Cunha BA, Connolly J, Abruzzo E (2015) Increase in pre-seasonal community-acquired Legionnaire's disease due to increased precipitation. Clin Microbiol Infect 21:e45-e46. https://doi.org/10.1016/j. cmi.2015.02.015

Dengler K, Keil C, Frech M, Gerz T, Kober K (2009) Comparison and validation of two high-resolution weather forecast models at Frankfurt airport. Meteorol Zeitschrift 18:531-542. https://doi.org/ 10.1127/0941-2948/2009/0399

Doms, G., Schättler, U., Baldauf, M., 2016. A description of the nonhydrostatic regional COSMO model part VII: User's guide. Deutscher Wetterdienst, Offenbach. http://www.cosmomodel.org/ content/model/documentation/core

Duguid H a, Stampfer JF (1971) The evaporation rates of small, freely falling water drops. J Atmos Sci 28:1233-1243. https://doi.org/10. 1175/1520-0469 (1971)028<1233:TEROSF >2.0.CO;2

Dupont JC, Haeffelin M, Protat A, Bouniol D, Boyouk N, Morille Y (2012) Stratus-fog formation and dissipation: a 6-day case study. Boundary-Layer Meteorol 143:207-225. https://doi.org/ 10.1007/s10546-012-9699-4

Egan JR, Hall IM, Lemon DJ, Leach S (2011) Modeling legionnaires' disease outbreaks: estimating the timing of an aerosolized release using symptom-onset dates. Epidemiology 22:188-198. https://doi. org/10.1097/EDE.0b013e31820937c6

Fisman DN, Lim S, Wellenius GA, Johnson C, Britz P, Gaskins M, Maher J, Mittleman MA, Victor Spain C, Haas CN, Newbern C (2005) It's not the heat, it's the humidity: wet weather increases legionellosis risk in the greater Philadelphia metropolitan area. J Infect Dis 192: 2066-2073. https://doi.org/10.1086/498248

García-Fulgueiras A, Navarro C, Fenoll D, García J, González-Diego P, Jiménez-Buñuales T, Rodriguez M, Lopez R, Pacheco F, Ruiz J, Segovia M, Baladrón B, Pelaz C (2003) Legionnaires' disease outbreak in Murcia, Spain. Emerg Infect Dis 9:915-921. https://doi.org/ 10.3201/eid0908.030337

Greig JE, Carnie JA, Tallis GF, Ryan NJ, Tan AG, Gordon IR, Zwolak B, Leydon JA, Guest CS, Hart WG (2004) An outbreak of legionnaires' disease at the Melbourne aquarium, April 2000: investigation and case-control studies. Med J Aust 180:566-572. https://doi.org/ 10.5694/J.1326-5377.2004.TB06093.X 
Hicks LA, Rose CE, Fields BS, Dress ML, Engel JP, Jenkins PR, Rouse BS, Blythe D, Khalifah AP, Feikin DR, Whitney CG (2007) Increased rainfall is associated with increased risk for legionellosis. Epidemiol Infect 135:811-817. https://doi.org/ 10.1017/S0950268806007552

Kao PM, Hsu BM, Chang TY, Hsu TK, Tzeng KJ, Huang YL (2015) Seasonal variation of Legionella in Taiwan's reservoir and its relationships with environmental factors. Environ Sci Pollut Res 22: 6104-6111. https://doi.org/10.1007/s11356-014-3819-2

Müller MD, Masbou M, Bott A (2010) Three-dimensional fog forecasting in complex terrain. Q J R Meteorol Soc 136:2189-2202. https:// doi.org/10.1002/qj.705

Nguyen TMN, Ilef D, Jarraud S, Rouil L, Campese C, Che D, Haeghebaert S, Ganiayre F, Marcel F, Etienne J, Desenclos J-C (2006) A community-wide outbreak of legionnaires disease linked to industrial cooling towers-how far can contaminated aerosols spread? J Infect Dis 193:102-111. https://doi.org/10.1086/498575

O'Brien SJ, Bhopal RS (1993) Legionnaires' disease: the infective dose paradox. Lancet 342:5-6. https://doi.org/10.1016/0140-6736(93)91877-O

Russo A, Gouveia CM, Soares PMM, Cardoso RM, Mendes MT, Trigo RM (2018) The unprecedented 2014 legionnaires' disease outbreak in Portugal: atmospheric driving mechanisms. Int J Biometeorol 62: 1167-1179. https://doi.org/10.1007/s00484-018-1520-8

Sakamoto R, Ohno A, Nakahara T, Satomura K, Iwanaga S, Kouyama Y, Kura F, Kato N, Matsubayashi K, Okumiya K, Yamaguchi K (2009) Legionella pneumophila in rainwater on roads. Emerg Infect Dis 15:1295-1297. https://doi.org/10. 3201/eid1508.090317

Schraff CH (1997) Mesoscale data assimilation and prediction of low stratus in the alpine region. Meteorog Atmos Phys 64:21-50. https://doi.org/10.1007/BF01044128

Seinfeld JH, Pandis SN (1998) Atmospheric chemistry and physics: from air pollution to climate change. Publ. New York Wiley 1998 Phys. Descr. xxvii 1326 p A WileyInterscience Publ. ISBN 0471178152 51:1-4. https://doi.org/10.1080/00139157.1999.10544295, Atmospheric Chemistry and Physics: From Air Pollution to Climate Change
Shivaji T, Sousa Pinto C, San-Bento A, Oliveira Serra LA, Valente J, Machado J, Marques T, Carvalho L, Nogueira PJ, Nunes B, Vasconcelos P (2014) A large community outbreak of legionnaires' disease in Vila Franca de Xira, Portugal, October to November 2014. Eurosurveillance 19, 20991. https://doi.org/10.2807/15607917.ES2014.19.50.20991

Stigler S (2015) Fisher and the 5\% level. CHANCE, 21:4, 12. https://doi. org/10.1080/09332480.2008.10722926

Ulleryd P, Hugosson A, Allestam G, Bernander S, Claesson BE, Eilertz I, Hagaeus A, Hjorth M, Johansson A, de Jong B, Lindqvist A, Nolskog P, Svensson N, (2012) Legionnaires' disease from a cooling tower in a community outbreak in Lidköping, Sweden- epidemiological, environmental and microbiological investigation supported by meteorological modelling. BMC Infect Dis 12, 313 . https://doi.org/10.1186/1471-2334-12-313

Vautard R, Yiou P, Van Oldenborgh GJ (2009) Decline of fog, mist and haze in Europe over the past 30 years. Nat Geosci 2:115-119. https://doi.org/10.1038/ngeo414

Walser SM, Gerstner DG, Brenner B, Höller C, Liebl B, Herr C (2014) Assessing the environmental health relevance of cooling towers - a systematic review of legionellosis outbreaks. Int J Hyg Environ Health 217:145-154. https://doi.org/10.1016/j.ijheh.2013.08.002

WMO, 2008. Guide to meteorological instruments and methods of observation [WWW document]. Guid. to Meteorol. Instruments Methods Obs. URL https://www.weather.gov/media/epz/mesonet/ CWOP-WMO8.pdf

Zak JA (1994) Drop size distributions and related properties of fog for five locations measured from aircraft. National Aeronautics and Space Administration, Langley Research Center [National Technical Information Service, distributor], Hampton Va: [Springfield, Va.] https://ntrs.nasa.gov/archive/nasa/casi.ntrs.nasa. gov/19940028559.pdf

Zhou Y, Benson JM, Irvin C, Irshad H, Cheng YS (2007) Particle size distribution and inhalation dose of shower water under selected operating conditions. Inhal Toxicol 19:333-342. https://doi.org/10. 1080/08958370601144241 